\title{
Forum
}

\section{Turbulence at the Shelf Break}

\author{
Michael Richey
}

It is generally held, I believe, by those who sail the oceans in small craft that the rapid changes of depth at the continental shelf break, where the soundings over a short distance decrease from thousands to hundreds of metres, can, in heavy weather, give rise to episodic or freak waves. There seems on the other hand little scientific evidence for this view, although a number of capsizes for such areas can be quoted.

Oceanographers tend to say that storm waves do not penetrate far enough below the surface for the sea bottom to have any effect at depths greater than about half the wavelength. It does, however, seem to be a common experience that in areas such as the vicinity of the shelf break in the Celtic Sea and Bay of Biscay heavy weather is attended by unusually turbulent seas.

When Jester was rolled and dismasted in $1986^{1}$ she was just at the shelf break south of the Great Sole Bank but with gusts of 80 knots it seemed unnecessary to seek further reasons for the turbulence. The following year, however, running under bare poles at 4 knots before a gale that never exceeded force 8 , in comparative comfort, she was suddenly overwhelmed by an immense breaking sea at a slight angle to the wave train that swept her along on her beam ends, the mast just below horizontal. She quickly righted herself but the wind vane had been swept off and the boom broken. The position was right at the shelf break north-west of Cape Finisterre.

My attention has been drawn to a number of yachts which have been knocked down or capsized in similar positions in relation to the continental shelf break. In 1982 Adfin's Rival was sunk by a single rogue wave near the Little Sole Bank. The Belgian yacht Trapegeer was repeatedly overcome and finally rolled with the loss of her mast in 1983 right on the shelf break south-west of Lorient. In 1983 a $37 \mathrm{ft}$ yacht designed by Robert Clark experienced three knockdowns in as many days off Cape Finisterre where Jester was knocked down in 1987. Although I missed the fact at the time, the only other knockdown I have experienced in Jester was in $198 \mathrm{I}$ coming back from Bermuda, just on the shelf south of Great Sole Bank. It broke the self-steering gear and I had to steer by hand for the remaining 250 miles or so of the voyage.

An investigation into the phenomenon (if such it is) could be useful in identifying areas where in certain conditions freak waves might be expected. Perhaps the first thing to establish is whether, in the view of those who frequent such waters (and one thinks straightaway of French, Spanish and Portuguese fishermen), the problem is identifiable.

The physics of episodic waves in deep water are perhaps imperfectly understood. Of the studies I have seen that relate to the continental shelf the most promising seems to be that by $\operatorname{Dr} A$. L. New of the Institute of Oceanographic Sciences, which postulates a steepening of surface waves by internal tides caused by rapid changes of depth at the shelf break (see, for example, 'Internal tidal currents in the Bay of Biscay') ${ }^{2}$ No doubt, too, much of the 'work initiated in 1978 by the Norwegian authorities under the general title 'Ships in Rough Sea' will be relevant. One of the objects of the study was 'to locate 
exposed areas in Norwegian waters where the probabilities of occurrence of extreme waves and breaking seas are most pronounced'.

\section{R EFER E N C ES}

1 Richey, M. W. (1987). Jester's ultimate storm. This Journal 40, 149.

2 New, A. L. (1987). Internal tidal currents in the Bay of Biscay, In Advances in Underwater Technology, Ocean Science and Offshore Engineering, Vol. 12, Modelling the Offshore Environment, pp. 279-293. London: Graham and Trotman, for SUT.

Comments on the foregoing note by Michael Richey have been received from a number of contributors.

\section{from Richard M. Clifford}

As a small-craft sailor who keenly observes any alteration in conditions around my vessel for indications of a deterioration in the weather or foul tidal stream or currents I have also noted a change at the shelf break and possibly also on the Mid-Atlantic Ridge. The observations are unscientific, but based on experience at sea in small craft.

Even in relatively calm weather one is aware of getting onto the continental shelf, particularly after several weeks in the ocean. The 'feel' of the sea changes. This sense of feel, possibly first noted by the delicate sensors in the middle ear, that the motion of the vessel is suddenly different is then confirmed by the eye noting a change in the wave formation and height of swell.

In gale or storm conditions establishing that one has crossed the continental shelf edge is less easy to confirm as judging wave height and turbulence is difficult from a small craft unless something untoward occurs such as a capsize. A knockdown or capsize of a yacht at sea is generally due to a large breaking wave catching the vessel on the beam either by broaching or when reaching, as happened to me on the shelf break 50 n.m. west of Ireland during the so called 1979 Fastnet Race storm. On that 14 August in Force 11 , I experienced several severe knockdowns between 0400 and $0800 \mathrm{~A}$. Later when running before the wind (and down the shelf break) with large breaking seas coming astern pitch poling became the problem, which may have been reduced when warps were streamed - a difficult task when having to steer dead down wind, alone. By $1400 \mathrm{~A}$ when on the continental shelf approaching Mizzen Head the seas were noticeably smaller, but that may have been due to a slight reduction in the wind.

In June and August 1976 when on or close to the North Atlantic Ridge in foul weather I was capsized in my $25 \frac{1}{2}-\mathrm{ft}$ yacht by large breaking waves. As I was below on both occasions it is not possible to comment on whether it was a freak wave that caught the vessel; however I have always considered it to be the case. Whether my proximity to the North Atlantic Ridge was relevant or not, is impossible to say.

Finally, although my numerous crossings of Biscay in small craft have so far been in congenial weather, its infamous reputation for turbulent seas may be as a result of the shelf-break phenomenon propounded by Mike Richey. The sailing ship and steamship routes across the Bay of Biscay cross the shelf break twice. 


\section{from Adrian L. New \\ (Institute of Oceanographic Sciences)}

In response to $M$. W. Richey's article in this Forum, it should be said that the shelf break in the Bay of Biscay is well known as an area of large tidal currents. ${ }^{t}$ The spring tide currents on the shelf are typically $\mathrm{I} \mathrm{kt}$ at maximum flow, but can reach ${ }_{1} \cdot 5 \mathrm{kt}$ in the $\mathrm{La}$ Chapelle Bank area. On the other hand, the currents in the deep ocean, only $30-40 \mathrm{~km}$ distant (to the SW roughly) are by comparison small, typically about $0^{\prime} \mathrm{I} \mathrm{kt}$. It seems that this relatively rapid change in currents, which can be augmented by the production of 'internal tidal' currents, can give rise to a significant steepening of storm waves (by as much as 25 per cent), and could affect shorter waves in an even more dramatic manner. ${ }^{2}$ The basic physical principle is that when the waves (imagined as travelling from the SW towards the shelf break) encounter an opposing current (e.g. at the time of maximum offshelf flow), this will tend to slow them down and cause a 'bunching' effect, with waves further out to sea travelling slightly more quickly and catching up with those nearer the shelf break. Since the waves must conserve their 'energy' it is easy to show that this 'bunching' or shortening of the waves must lead to an increase in their amplitude. This increase in amplitude is consequently directly associated with the rapidly-changing water depth over the continental slope, and would probably have a maximum effect close to the edge of the shelf break. This conjecture, which could now be tested with modern remote-sensing techniques, seems to be in qualitative agreement with the observations and experiences of Mr Richey.

\section{REFERENCES}

1 Pingree, R. D., Griffiths, D. K. and Mardell, G. T. (1983). The structure of the internal tide at the Celtic Sea shelf break. J. Mar. Biol. Ass., 64, 99-113.

${ }^{2}$ New, A. L. (1987). Internal tidal currents in the Bay of Biscay, In Advances in Underwater Technology, Ocean Science and Offshore Engineering, Vol. 12, Modelling the Offshore Environment, pp. 279-293. London: Graham and Trotman, for SUT.

\section{from Roger H. Motte \\ (Plymouth Polytechnic)}

It appears likely from observations by experienced mariners that abnormal wave conditions can exist, on occasions, at the continental edge. Dr R. D. Pingree (1985) identified in a recent paper $^{1}$ a group of waves off the Great Sole Bank which may be so considered.

Three of the internal wave packets were clearly identified by the ship's radar and a special study was made following a single wave group. The surface signatures of these internal waves could also be seen visually. Parallel 'walls of white water' (breaking surface waves) separated by about $\mathrm{I} \mathrm{km}$ and stretching for several miles indicating the presence of the internal waves.

Personal correspondence with Dr Pingree at the Plymouth Marine Laboratories elicited the following response. "There can be little doubt that internal waves and tides, generated at the shelf break, affect the steepness of surface gravity waves, in the summer at least.' (The above incident occurred in the summer.)

It is my own opinion that if a generating mechanism exists in summer, then it probably exists in winter too. The mechanism may be associated with the transfer of energy flux brought on by the steep shelving topography. It is merely easier to observe and measure during the summer months when other contributions are at a minimum. (Theory 
suggests that waves are affected in their translation by entering depths of water of half their wavelength, the shoaling affect.)

Most mariners must now be aware of the principle of the theories of frequency spectra related to ocean waves. An isolated or freak wave may have several harmonized contributions within it, all of which are 'in phase' at the particular time of observation. Hence the large amplitude of a so called freak wave.

Contributions may include not only the effect of wind on sea surface to generate a sea wave in situ, in addition to shoaling effects, but also externally generated swells which may have travelled thousands of miles to make their contribution.

Comparisons of sea spectra with meteorological charts of the North Atlantic indicates that swell arriving from a distant storm shows a narrow band of periods, and its significant period decreases with time.

Observations in general show that the longest period exhibited by swell due to a distant storm is proportional to the maximum wind velocity in the storm and does not depend upon fetch or duration of the wind.

The swell effects can be manifest over very large distances and this has been measured in the Western Approaches. Thus low swell has been received from a tropical storm off the coast of Florida almost 3000 miles away in Cornwall and from a Cape Horn storm 7000 miles away. ${ }^{2}$ These phenomena were measured and reported over 40 years ago.

Like many sea-features there is no simple answer but rather a combination of mechanisms which need to be understood.

\section{REF ER E N C ES}

1 Pingree, R. D. and Mardell, G. T. (1985). Solitary internal waves in the Celtic Sea. Prog. Oceanog., 14, 431 .

${ }^{2}$ Barber, N. and Ursell, F. (1 947). A Letter to the editor. Nature, (Lond.), 159, 205.

\section{NOTE}

At the request of the editor, Professor Motte very kindly attempted to obtain the views of local West-Country fishermen on the occurrence of abnormal waves near the shelf break. He reports that they seemed reluctant to pass any remark other than, 'They buggers is out there all right'.

\section{from David M. Page}

I was interested in Michael Richey's comments on this subject. As a young watchkeeper I could not understand why, when the ship came into soundings in the Western Approaches, if there was any sea running, there would be a distinct area of rougher water. Older seamen seemed to accept the phenomenon as a fact of life and I can remember on one occasion receiving a lecture from my Captain, the main thrust of which was that not everything is covered by the textbooks - I had been reading up on trochoidal wave forms and had the temerity to suggest the water was too deep for waves to be affected by the sea bed. The discussion caused me to observe the sea state in the vicinity of the 100 fathom line on subsequent voyages and I was able to satisfy myself that in most cases there was a noticeable change in the wave pattern. Perhaps, as Michael Richey suggests, this change is brought about by internal tides at the shelf break.

The following passage from Claud Worth's log in Tern III, Coruna to Falmouth, June 1920, may be of interest: 'The Northerly wind has knocked up a considerable sea which has become distinctly steeper since we crossed the roo fathom line.' 


\section{from Helmuth Sandstrom \\ Bedford Institute of Oceanography}

Michael Richey has drawn attention to a number of small sailing vessels which have been knocked down or capsized by freak waves at or near the continental shelf break. The common experience seems to be that, in the vicinity of the shelf break, especially in the Celtic Sea and Bay of Biscay, heavy weather is attended by unusually turbulent seas.

Although the direct effect of the sea bottom on the storm waves is small, the abrupt depth changes which characterize the edges of the continental shelves lead to other oceanographic processes that can modify the sea. The steep bottom slopes are responsible for trapping and guiding low-frequency currents and are considered the prime sites of generation of internal tides and associated phenomena. It is in the interaction with the currents that a reasonable explanation to the modified sea must be sought.

Studies by Pingree and coworkers ${ }^{1}$ have shown that in the Bay of Biscay and Celtic Sea the internal tide is very large (peak-to-trough values of over $50 \mathrm{~m}$ at spring tides), and propagates both on-shelf towards the coast and off-slope towards the ocean. The very large amplitudes cause the internal tide to become almost bore-like, followed by a group of undulations which are commonly called internal solitary waves. The effect of the internal tidal bore is a rapid increase of current flowing in the direction of bore motion. The wave-current interaction to first order is summed up in the following sketch.

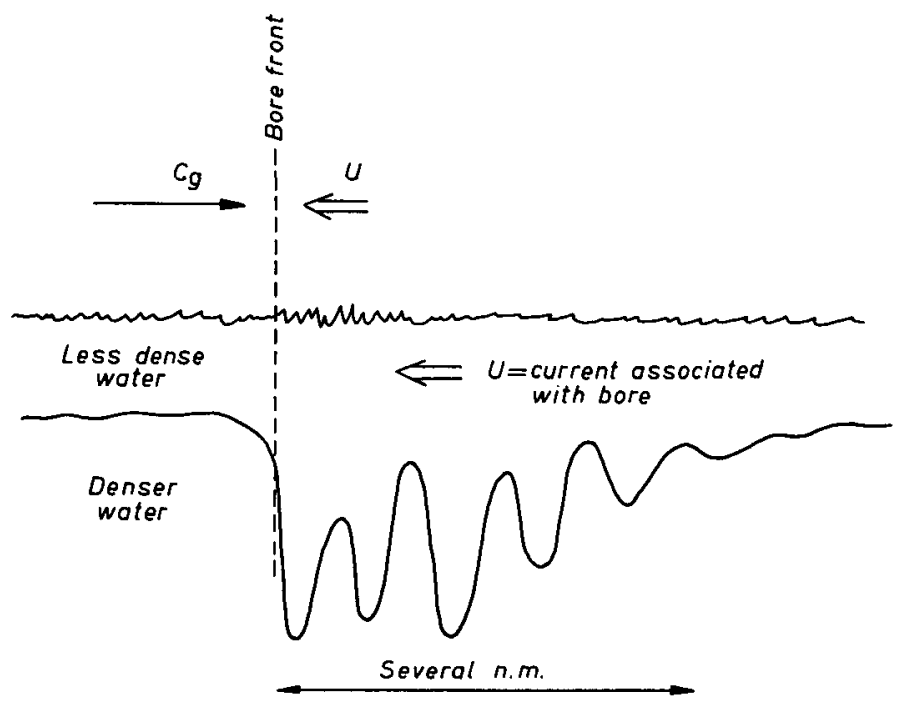

Fig. I. Sketch of an internal tidal bore moving to the left

Assume that outside the bore the waves behave as typical deep-water storm waves with wave energy propagating at the appropriate group velocity, $C_{\mathrm{g}}$. As the waves enter the tidal bore, the effective propagation speed is reduced to $\left(C_{\mathrm{g}}-U\right)$. As a result there are more waves per unit distance in the bore than outside and the wave energy per unit area has to increase accordingly.

As an example, consider waves with period $=10 \mathrm{~s}$, for which $C_{\mathrm{g}} \approx 15 \mathrm{kt}$, and assume $U={ }_{3} \mathrm{kt}$. The energy density increases in the ratio of $C_{\mathrm{g}} /\left(C_{\mathrm{g}}-U\right)=5 / 4$. This is a substantial increase in energy and if the sea is already fully developed, as it would be in stormy conditions, even a small increase in energy will lead to a significant increase in wave breaking and associated turbulence. This is to rid the waves of the additional energy 
and bring the sea back to a fully developed state. One notes that the energy increases proportionately more for shorter waves because of their slower speed, adding to the apparent roughness of the sea.

In the sketch the waves and the tidal bore propagate in opposing directions, but a similar argument can be made when the angle of approach is oblique, and applies as well when the waves encounter a stationary current, although the effects are correspondingly smaller. As the waves adjust themselves to a new environment, other processes may be of importance, but the principle of 'wave action conservation' described above is certainly the dominant process at the boundary of different oceanographic regimes.

\section{REFERENCES}

1 Pingree, R. D. et al. ( 1983$)$. The structure of the internal tide at the Celtic Sea shelf break. J. Mar. Biol. Ass., 64, 99-г 3 . 